Original Research

\title{
The Comparison of Progressive Muscle Relaxation Frequency on Anxiety, Blood Pressure, and Pulse of Haemodialysis Patients
}

\author{
Kusnanto Kusnanto', Maulana Arif Murtadho², Lilik Herawati ${ }^{3}$ and Hidayat Arifin ${ }^{2}$ \\ ${ }^{1}$ Faculty of Nursing, Universitas Airlangga, East Java, Indonesia \\ 2 Master of Nursing Program, Faculty of Nursing, Universitas Airlangga, Surabaya, Indonesia \\ ${ }^{3}$ Faculty of Medicine, Universitas Airlangga, Surabaya, Indonesia
}

\begin{abstract}
Introduction: Haemodialysis is one of the kidney replacements therapies, but, as it cannot wholly replace kidney function, it still causes complications such as increased blood pressure and pulse which can lead to anxiety for the patient. The purpose of this study was to explain the effect of Progressive Muscle Relaxation (PMR) on anxiety, blood pressure and pulse in haemodialysis patients.

Methods: The study design was a true pre-post-test control group design experiment. The total sample was 105 haemodialysis patients taken by purposive sampling technique and divided into two intervention groups and one control group. The independent variable was PMR, and the dependent variables were anxiety, blood pressure and pulse. Data were obtained using a questionnaire and analysed using the Kruskal Wallis Test and Mann-Whitney U test with a significance level $<0.05$.

Results: The results of the PMR two times per week group analysis for one month showed a significant influence on anxiety $(p=0.000)$, blood pressure $(p=0.000)$, and pulse rate $(\mathrm{p}=0.000)$. Mann-Whitney $U$ Test Results showed a significant effect on anxiety $(p=0.004)$, blood pressure $(p=0.000)$, and pulse $(p=0.000)$.

Conclusion: Haemodialysis patients who performed PMR interventions showed a promising outcome on a decrease in anxiety, blood pressure and pulse. The regular application of PMR interventions can control vital signs in patients undergoing haemodialysis
\end{abstract}

\section{ARTICLE HISTORY}

Received: October 16, 2019

Accepted: December 02, 2019

\section{KEYWORDS}

haemodialysis; progressive muscle relaxation; anxiety; blood pressure; pulse

\section{CONTACT}

Kusnanto Kusnanto $\triangle$ kusnanto@fkp.unair.ac.id $\risingdotseq$ Faculty of Nursing, Universitas Airlangga East Java, Indonesia

Cite this as: Kusnanto, K., Murtadho, M. A., Herawati, L., \& Arifin, H. (2019). The Comparison of Progressive Muscle Relaxation Frequency on Anxiety, Blood Pressure, and Pulse of Haemodialysis Patients. Jurnal Ners, 14(1), 69-74. doi:http://dx.doi.org/10.20473/jn.v14i1.15700

\section{INTRODUCTION}

Chronic Kidney Disease (CKD) is a problem that is often found in the community; in its journey, if it reaches to stage five, it will require kidney replacement therapy in the form of kidney transplantation or dialysis (KDIGO, 2013; Tomson \& Taylor, 2015). Between the two types of replacement therapy, dialysis is a standard therapy carried out and haemodialysis (HD) is a procedure that results in the rest of metabolism, and excess fluid is removed from the blood through the artificial kidney (Amini, Goudarzi, Masoudi, Ahmadi, \& Momeni, 2016). Haemodialysis cannot heal and is unable to compensate for the loss of metabolic or endocrine activity carried out by the kidneys, so that patients continue to experience complications, including increased blood pressure and pulse that cannot be controlled. Studies estimating CKD prevalence with HD in general populations worldwide found a consistent rate estimated of $11-13 \%$ ( $\mathrm{Li}$, Jiang, $\mathrm{Wu}$, Xu, \& Miao, 2017; Qureshi, Lorch, \& Navaneethan, 2017; Rahimlu, Shab-bidar, \& Djafarian, 2017; Trapp et al., 2014; Valika \& Peixoto, 2016). The complication raises new more complex problems, including anxiety (Kokoszka et al. 2016). Anxiety in patients who do HD often lacks people's attention, even though the psychological burden experienced by HD patients can affect health and treatment (Li et al., , , 2016). Anxiety is a major factor that can reduce the health of HD patients. In our study site location, the interventions are given to patients to reduce anxiety with health education, and there are no additional interventions. 
Further efforts are needed to reduce anxiety, blood pressure and pulse experienced by HD patients.

The proportion of the global population with anxiety disorders in 2015 was estimated at 3.6\%. Depression and anxiety disorders are more common in women than men ( $4.6 \%$ compared to $2.6 \%$ at the global level). The data showed the prevalence of emotional, and mental diseases as indicated by symptoms of depression and anxiety for ages 15 years and older, reaching around 14 million people or 6\% of the total population of Indonesia (Riskesdas, 2018). In the blood pressure and pulse rate of 100 haemodialysis patients, an estimated 80 patients experienced changes in both.

One of the essential intradialytic complications to evaluate is cardiovascular problems because it causes an increase in morbidity and mortality in CKD patients undergoing routine haemodialysis (Shin, Yeo, Hong, Hwang, \& Kim, 2018). Cardiovascular complications can include blood pressure and pulse that cannot be controlled. In increased blood pressure often associated with renin, fluid overload and sympathetic nerves, these sympathetic nerves also affect the pulse rate in haemodialysis patients. (Li et al, 2017). All complications arising will increase the anxiety felt by the patient. The anxiety in sedentary HD patients can contribute to disease progression and worsen the prognosis (Li et al., 2016). The intervention to minimise complications is usually pharmacological and non-pharmacological therapies, but, due to a disruption in kidney function, an alternative that can be used is non-pharmacological therapy.

PMR is a relaxation technique through two processes, namely tensing and relaxing the muscles of the body, which is a combination of breathing and movement exercises (Mhaske, Poovishnu Devi, \& Jagtap, 2018). PMR can reduce anxiety for five times per week (Ramasamy, Panneerselvam, Govindharaj, Kumar, \& Nayak, 2018); improved physical function (Ublosakka-Jones, Tongdee, Pachirat, \& Jones, 2018); sleeping disorder Seyedi Chegeni, Gholami, Azargoon, Hossein Pour, Birjandi, \& Norollahi, 2018), mental (Li et al., 2015); and quality of life (Ramasamy et al., 2018). Implementation of PMR for five times per week can reduce patient anxiety in the hospital (Amini, Goudarzi, Masoudi, Ahmadi, \& Momeni, 2016; Ramasamy, Panneerselvam, Govindharaj, Kumar, \& Nayak, 2018), while research conducted by Li et al. (2015) states giving it three times per week can reduce anxiety. The success of an exercise is also determined by the frequency performed. Based on the explanation above, research is needed to analyse the effect of the comparison of PMR frequency two times per week for one month and one time per week on anxiety, blood pressure and pulse frequency in HD patients.

\section{MATERIALS AND METHODS}

The research was true-experimental with pre-posttest control group design. The population was 192 haemodialysis patients at " $\mathrm{X}$ " Hospital in East Java Province. The total samples were 105 people obtained by purposive sampling with inclusion criteria 1) conscious and cooperative patients (compos mentis) and cooperative; 2 ) aged $>18$ years; 3 ) having HD for $>2$ months, and undergoing HD twice per week; 4) systolic blood pressure between 120 $160 \mathrm{mmHg}$, and diastole between $80-110 \mathrm{mmHg}$ before HD; and 5) pulse between 70-100 x per minute before HD. The exclusion criteria included: 1) the patient having chronic unstable heart disease; 2) the patient experiences neuromusculoskeletal system disorders such as chronic injuries, fractures, increased intracranial pressure, severe coronary artery disease, and is pregnant; and 3) being weak (haemoglobin $(\mathrm{HB})<8$ ). The dropout criteria: 1) respondents resign during the study; 2) respondents are not cooperative in answering the questionnaire given; 3) respondents who did not follow the intervention more than three times in a row and did not take the post-test; and 4) respondents move haemodialysis. The independent variable was the progressive muscle relaxation intervention and the dependent variables were the change in anxiety, blood pressure and pulse. Anxiety was measured with the Covi Anxiety Scale (Lipman \& Covi, 1981) which consists of a quantitative anxiety assessment. Blood pressure was measured using an automatic tensiometer, and a pulse with palpation which was then documented on the observation sheet. The collected data were analysed by Kruskal Wallis to analyse differences between groups (treatment 1, treatment 2, and control) and Wilcoxon Signed Rank Test to find out the difference between pre-test and post-test in each group. The researchers assessed the anxiety score using the Covi Anxiety Scale Questionnaire sheet in order to obtain an initial score before the intervention. Then, the researchers conducted a matching technique based on the level of scoring results to try to maintain the homogeneity of respondents and divide respondents into treatment 1 (PMR group two times per week for one month) with 35 respondents, treatment 2 (PMR group once per week for one month) with 35 respondents, and the control group with 35 respondents. After four weeks of intervention, a post-test was conducted on both groups as an evaluation using the Covi Anxiety Scale questionnaire. This study has obtained ethical eligibility from the Health Research Ethics Committee of "X" Hospital with Number 893.3/1873/438.6.7/2019.

\section{RESULTS}

The results of studies on the variables anxiety, blood pressure (systole and diastole) and pulse can be seen in Table 1 with 105 respondents. The results of the study on anxiety variables found a significant difference in the significance of anxiety changes in treatment 1 with the control group, obtaining a $\mathrm{p}=0.004$ which means that treatment 1 was a change in anxiety compared with the control group. Whereas 
Table 1. The intervention of progressive muscle relaxation two times per week for one month (treatment 1) and one time per week for one month (treatment 2) for changes in anxiety, blood pressure (systole and diastole) and pulse.

\begin{tabular}{|c|c|c|c|c|c|c|c|c|c|}
\hline Variables & Pre & p* & Post & p* & Delta & p* & Mean \pm SD & $\mathbf{p}^{* *}$ & $\mathbf{p}^{* * *}$ \\
\hline \multicolumn{10}{|l|}{ Anxiety } \\
\hline Treatment 1 & $9.91 \pm 2.120$ & 0.000 & $9.31 \pm 2.153$ & 0.017 & $-0.60 \pm 0.497$ & 0.000 & $-0.60 \pm 0.497$ & \multirow{3}{*}{0.015} & 0.004 \\
\hline Treatment 2 & $9.91 \pm 2.120$ & 0.000 & $9.51 \pm 2.049$ & 0.025 & $-0.40 \pm 0.497$ & 0.000 & $-0.40 \pm 0.497$ & & 0.207 \\
\hline Control & $9.91 \pm 2.120$ & 0.000 & $9.66 \pm 2.169$ & 0.001 & $-0.26 \pm 0.443$ & 0.000 & $-0.26 \pm 0.443$ & & 0.009 \\
\hline \multicolumn{10}{|c|}{ Systole Blood Pressure } \\
\hline Treatment 1 & $144.86 \pm 12.455$ & 0.004 & $138.14 \pm 12.25$ & 0.064 & $-8.14 \pm 4.864$ & 0.000 & $-8.14 \pm 4.864$ & \multirow{3}{*}{0.000} & 0.000 \\
\hline Treatment 2 & $139.14 \pm 11.973$ & 0.000 & $135.57 \pm 11.09$ & 0.007 & $-3.57 \pm 3.109$ & 0.000 & $-3,57 \pm 3,109$ & & 0.019 \\
\hline Control & $140.86 \pm 11.973$ & 0.000 & $139.00 \pm 9.985$ & 0.001 & $-1.86 \pm 2.451$ & 0.000 & $-1.86 \pm 2.451$ & & 0.000 \\
\hline \multicolumn{10}{|c|}{ Diastole Blood Pressure } \\
\hline Treatment 1 & $93.14 \pm 7.960$ & 0.000 & $86.14 \pm 6.427$ & 0.000 & $-7.00 \pm 4.236$ & 0.000 & $-7.00 \pm 4.236$ & \multirow{3}{*}{0.000} & 0.000 \\
\hline Treatment 2 & $89.71 \pm 6.636$ & 0.000 & $85.71 \pm 5.959$ & 0.017 & $-4.00 \pm 4.166$ & 0.000 & $-4,00 \pm 4,166$ & & 0.005 \\
\hline Control & $88.00 \pm 9.010$ & 0.000 & $86.43 \pm 7.130$ & 0.004 & $-1.57 \pm 2.913$ & 0.000 & $-1.57 \pm 2.913$ & & 0.006 \\
\hline \multicolumn{10}{|c|}{ 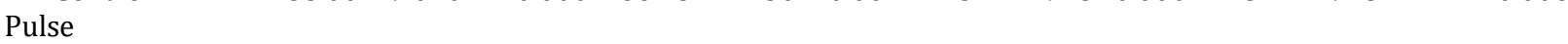 } \\
\hline Treatment 1 & $83.83 \pm 1.706$ & 0.001 & $80.63 \pm 1.262$ & 0.000 & $-3.20 \pm 1.828$ & 0.000 & $-3.20 \pm$ & \multirow{3}{*}{0.000} & 0.000 \\
\hline Treatment 2 & $83.14 \pm 2.074$ & 0.000 & $81.37 \pm 1.800$ & 0.000 & $-1.77 \pm 1.516$ & 0.000 & $-1,77 \pm 1,516$ & & 0.009 \\
\hline Control & $82.29 \pm 2.177$ & 0.000 & $81.43 \pm 1.720$ & 0.000 & $-0.86 \pm 1.115$ & 0.000 & $-0.86 \pm 1.115$ & & 0.001 \\
\hline \multicolumn{10}{|c|}{ Treatment 1: PMR two times per week for one month } \\
\hline \multicolumn{10}{|c|}{ Treatment 2: PMR once per week for one month } \\
\hline \multicolumn{10}{|c|}{$p^{*}$ normality test, Shapiro Wilk (normal p-value 0.05) } \\
\hline \multicolumn{10}{|c|}{$p^{* *}$ Kruskal Wallis ( $p$-value 0.05) } \\
\hline \multicolumn{10}{|c|}{$p^{* * *}$ Wilcoxon Signed Rank Test ( $p$-value 0.05) } \\
\hline
\end{tabular}

in treatment 2 compared to the control group, it could be interpreted that there was no significant difference because of obtaining a p-value of 0.05 . In the comparison of treatment 1 and treatment 2 it can be interpreted that there was no significant difference, with p-value 0.05 . Treatment 1 affects anxiety; this is indicated by the difference in anxiety values in treatment 1 , treatment 2 and control group.

The results of the study are that blood pressure systole variable showed differences in systolic blood pressure in treatment 1 with the control group obtaining a $p=0.000$. This means that treatment 1 was a change in systolic blood pressure compared to the control group. With treatment 2 compared to the control group, it can be interpreted that there was a significant difference, with $\mathrm{p}=0.019$, whereas in the comparison of treatment 1 and treatment 2 , it can be interpreted that there was a significant difference, with $p=0.000$. Treatment 1 was the most effective in changes in systolic blood pressure compared to treatment 2; this is indicated by the difference in anxiety values in treatment 1 , treatment 2 and the control group.

The results of the study on the blood pressure diastole variable obtained significant diastole blood pressure differences in the three groups. It showed a significant difference with $\mathrm{p}=0.000$, which means that treatment 1 was the best group in diastolic blood pressure changes compared to treatment 2 and control. Thus, it can be concluded that implementation of treatment 1 has an effect on diastolic blood pressure; this is indicated by the difference in the value of diastolic blood pressure in treatment 1 , treatment 2 and the control group.

The results of the study on the pulse variable obtained a significant difference in the pulse rate in the three groups and showed a significant difference with a value of $p<0.000$, which means that treatment 1 affected the change in pulse rate of haemodialysis patients compared to treatment 2 and the control group. Thus, it can be concluded that implementation of treatment 1 was the most effective against changes in pulse; this is indicated by the difference in the value of pulse changes in treatment 1 , treatment 2 and the control group.

\section{DISCUSSION}

\section{Anxiety}

Variable change in anxiety in the progressive muscle relaxation group two times per week for one month showed a significant decrease, which means there was an influence of PMR two times per week for one month compared to the control group. The progressive muscle relaxation group one time per week for one month showed no significant decrease, which means there was no effect of PMR one time per week for one month compared to the control group. Whereas the comparison of the progressive muscle relaxation group two times per week for one month and the progressive muscle relaxation group one time per week for one month showed a nonsignificant decrease, which means that the administration of PMR two times per week for one month and PMR one time per week for one month were both effective on anxiety changes in haemodialysis patients. However, the PMR group two times per week for one month showed a more effective value when compared to the PMR group one time per week for one month and the control group.

The results of this study are consistent with other studies that show that progressive muscle relaxation can reduce anxiety. Research conducted by Ramasamy, Panneerselvam, Govindharaj, Kumar, and Nayak (2018) states that progressive muscle 
relaxation two times a day for 5-6 days per week can reduce anxiety in leprosy patients who are hospitalised. Mhaske, Poovishnu Devi, and Jagtap (2018) state that progressive muscle relaxation two times a day for five days per week can reduce anxiety and depression in patients with chronic obstructive pulmonary disease. Progressive muscle relaxation interventions were more effective in reducing anxiety, fatigue and improving the sleep quality of patients with chronic kidney failure undergoing haemodialysis (Seyedi Chegeni et al. 2018). Progressive muscle relaxation is effective in reducing anxiety, depression and improving mental health in patients with pulmonary arterial hypertension.

Progressive muscle relaxation causes contraction of skeletal muscle fibres which leads to a sensation of muscle tension. In this case, the central nervous system involving the sympathetic nerves and the parasympathetic nervous system. Some organs are affected by these two nervous systems between sympathetic and parasympathetic work reciprocity. The activity of the parasympathetic nervous system is also called trophotropic, which can cause feelings of wanting to rest and physical repair of the body. The parasympathetic response includes a decrease in pulse and blood pressure, increased blood flow and suppression of tension and anxiety. Therefore, progressive muscle relaxation exercises can bring a relaxation response so that it can achieve a state of calm and stress will decrease. Comfortable feelings are passed on to the hypothalamus to produce Corticotropin-Releasing Factor (CRF). The CRF stimulates the pituitary gland to increase the production of endorphin, enkephalin and serotonin which can ultimately increase patient comfort. Feeling comfortable and relaxed can cause anxiety to decrease (Smeltzer, Bare, \& Hinkle, 2015).

In this study, demographic characteristics between groups are the same. Thus it does not affect the results. The researchers believe that the change in anxiety in this study occurred due to the influence of progressive muscle relaxation two times per week for one month, which stimulates the pituitary gland to increase endorphin production, which can ultimately increase patient comfort. This comfortable and relaxed feeling can cause a decrease in anxiety, blood pressure and pulse rate (Smeltzer et al., 2015). In the control group, most respondents did not experience changes in anxiety, this is because respondents in the control group only received health education and the absence of interventions that could increase comfort caused anxiety in most patients in the control group to not decrease.

\section{Blood pressure}

In the variable changes in blood pressure, the progressive muscle relaxation group two times per week for one month showed a significant decrease, which means there was an influence of PMR two times per week for one month compared to the control group. The progressive muscle relaxation group one time per week for one month showed a significant decrease, which means there was an effect of PMR one time per week for one month compared to the control group. Whereas the comparison of the progressive muscle relaxation group two times per week for one month and the progressive muscle relaxation group one time per week for one month showed a significant decrease, meaning that the administration of PMR two times per week for one month was more effective when compared to the PMR one time per week for one month in regard to changes in blood pressure in haemodialysis patients.

The results of this study are consistent with other studies that show that progressive muscle relaxation can reduce blood pressure. Research conducted by Rosdiana and Cahyati (2019) states that progressive muscle relaxation once a day for seven days can lower blood pressure in hypertensive patients ). Herawati and Azizah (2016) stated that progressive muscle relaxation two times a day for seven days can reduce systolic blood pressure in hypertensive patients. With progressive muscle relaxation interventions, blood pressure in hypertensive patients are more likely to fall than without progressive muscle relaxation (Sulaeman, 2018). Progressive muscle relaxation is effective in reducing blood pressure in hypertensive patients (Arisjulyanto, 2019). This comfortable and relaxed feeling can cause blood pressure to decrease (Herawati \& Azizah, 2016).

In this study, the demographic characteristics between the PMR groups of the control group were the same, so that they did not affect the results. The researchers believe that changes in blood pressure in this study occurred because of the effect of progressive muscle relaxation that stimulates the pituitary gland to increase endorphin production, which can ultimately increase patient comfort. This comfortable and relaxed feeling can cause a decrease in blood pressure (Herawati \& Azizah, 2016). In the control group, most of the respondents did not experience changes in blood pressure; this is because respondents in the control group only received health and the absence of interventions that can increase the sense of comfort and relaxation caused blood pressure in most patients in the control group to not decrease.

\section{Pulse}

In the variable pulse change, the progressive muscle relaxation group two times per week for one month showed a significant decrease, which means there was an influence of PMR two times per week for one month compared to the control group. The progressive muscle relaxation group one time per week for one month also showed a significant decrease, which means there was an effect of PMR one time per week for one month compared to the control group. Whereas the comparison of the progressive muscle relaxation group two times per week for one month and the progressive muscle relaxation group one time per week for one month showed a significant decrease, meaning that the administration of PMR two times per week for one month was more effective 
when compared to the PMR one time per week for one month on changes in pulse in haemodialysis patients.

The results of this study are in agreement with other studies that show that progressive muscle relaxation can reduce the pulse rate. Research conducted by Khanna (2007) states that progressive muscle relaxation once a day for ten consecutive days can reduce the pulse rate in women with high-stress levels (Khanna, Paul, \& Sandhu, 2007). Progressive muscle relaxation interventions two times per week can reduce the pulse rate in surgical patients (Ko \& Lin, 2012). Intervention of progressive muscle relaxation, two times per week for one month meant the pulse rate and stress in students decreased (Shinde, Kini, Naik, \& Desousa, 2015).

High pulse in haemodialysis patients can be caused by anxiety experienced. Anxiety occurs due to the stimulation of the endocrine and autonomic systems. Hyperactivity to stimulants in the autonomic nerve due to anxiety can affect several organs and results in other symptoms, such as increased pulse rate. In this study, the demographic characteristics between the PMR groups of the control group were the same, so that they did not affect the results. The researchers believe that the change in pulse rate in this study occurred due to the effect of progressive muscle relaxation which stimulates the pituitary gland to increase endorphin production, which can ultimately increase patient comfort. This feeling of comfort and relaxation can cause a decrease in pulse (Herawati \& Azizah, 2016). In the control group, most respondents did not experience a change in pulse, and this is because respondents in the control group only received health education and the absence of interventions that could increase the sense of comfort and relaxation which caused the pulse rate in most patients in the control group to not decrease.

\section{CONCLUSION}

From the results of the study it can be concluded that increasing the intensity of PMR interventions can have a positive effect on reducing anxiety levels, controlled blood pressure and regular pulse. It is hoped that further researchers will be able to develop PMR methods that can be effective and be used to resolve health problems in haemodialysis patients or others. The contribution of the study is in affording new information and techniques to maintain anxiety, blood pressure and pulse of haemodialysis patients. The application of PMR interventions can be given by nurses regularly to patients undergoing haemodialysis so that vital signs, including anxiety, blood pressure and pulse, can be controlled.

\section{LIMITATION}

Limitations in this study are that it only uses the progressive muscle relaxation group two times per week for one-month, progressive muscle relaxation one times per week for one month and the control group. Thus, it was necessary to add sufficient interventions as a comparison to see the effectiveness of progressive muscle relaxation therapy.

\section{REFERENCES}

Amini, E., Goudarzi, I., Masoudi, R., Ahmadi, A., \& Momeni, A. (2016). Effect of Progressive Muscle Relaxation and Aerobic Exercise on Anxiety, Sleep Quality, and Fatigue in Patients with Chronic Renal Failure Undergoing Hemodialysis. International Journal of Pharmaceutical and Clinical Research, 8(12), 1634-1639.

Arisjulyanto, D. (2019). The Effect of Progressive Muscle Relaxation Techniques to Decrease Blood Pressure for Patients with Hypertension in Mataram. Primary Health Care Open Access, 08(04), 10-13. https://doi.org/10.4172/21671079.1000309

Herawati, I., \& Azizah, S. N. (2016). Effect of Progressive Muscle Relaxation Exercise To Decrease Blood Pressure. International Conference on Health and Well-Being (ICHWB), 405-412.

KDIGO, (Kidney Disease: Improving Global Outcomes). (2013). KDIGO 2012 Clinical Practice Guideline for the Evaluation and Management of Chronic Kidney Disease. Kidney International Supplements, 3(1), 4-4. https://doi.org/10.1038/kisup.2012.76

Khanna, A., Paul, M., \& Sandhu, J. S. (2007). Efficacy of two relaxation techniques in reducing pulse rate among highly stressed females.Calicut Medical Journal, 5(5), 6-8.

Ko, Y. L., \& Lin, P. C. (2012). The effect of using a relaxation tape on pulse, respiration, blood pressure and anxiety levels of surgical patients. Journal of Clinical Nursing, 21(5-6), 689-697. https://doi.org/10.1111/j.13652702.2011.03818.x

Kokoszka, A., Leszczyńska, K., Radzio, R., Daniewska, D., Łukasiewicz, A., Orzechowski, W., ... Gellert, R. (2016). Prevalence of depressive and anxiety disorders in dialysis patients with chronic kidney disease. Archives of Psychiatry and Psychotherapy, 18(1),

8-13. https://doi.org/10.12740/APP/61977

Li, X., Jiang, Q., Wu, W., Xu, X., \& Miao, L. (2017). Nighttime blood pressure and pulse wave velocity in dialysis patients. Clinical and Experimental Nephrology, 22(1), 173-178. https://doi.org/10.1007/s10157-017-1464-z

Li, Y.-N., Shapiro, B., Kim, J. C., Zhang, M., Porszasz, J., Bross, R., ... Kopple, J. D. (2016). Association between quality of life and anxiety, depression, physical activity and physical performance in maintenance hemodialysis patients. Chronic Diseases and Translational Medicine, 2(2), 110119. https://doi.org/10.1016/j.cdtm.2016.09.004 Li, Y., Wang, R., Tang, J., Chen, C., Tan, L., Wu, Z., ... Wang, X. (2015). Progressive Muscle Relaxation Improves Anxiety and Depression of Pulmonary Arterial Hypertension Patients. Evidence-Based Complementary and Alternative Medicine, 2015, 1- 
8. https://doi.org/10.1155/2015/792895

Lipman, R., \& Covi L, D. R. (1981). Pharmacotherapy of anxiety and depression. Psychopharmacology Bulletin, 17(3), 91-103.

Mhaske, M. M., Poovishnu Devi, T., \& Jagtap, V. K. (2018). Comparison of the effectiveness of visual imagery technique and progressive relaxation technique on anxiety and depression in subjects with moderate chronic obstructive pulmonary disease. Asian Journal of Pharmaceutical and Clinical Research, 11(6), 318-323. https://doi.org/http://0-

dx.doi.org.wam.leeds.ac.uk/10.22159/ajpcr.2018. v11i6.25067

Qureshi, S., Lorch, R., \& Navaneethan, S. D. (2017). Blood Pressure Parameters and their Associations with Death in Patients with Chronic Kidney Disease. Current Hypertension Reports, 19(11), 92. https://doi.org/10.1007/s11906-017-0790-6

Rahimlu, M., Shab-bidar, S., \& Djafarian, K. (2017). Body Mass Index and All-cause Mortality in Chronic Kidney Disease : A Dose - response Metaanalysis of Observational Studies. Journal of Renal Nutrition, 27(4), 225-232. https://doi.org/10.1053/j.jrn.2017.01.016

Ramasamy, S., Panneerselvam, S., Govindharaj, P., Kumar, A., \& Nayak, R. (2018). Progressive muscle relaxation technique on anxiety and depression among persons affected by leprosy. Journal of Exercise Rehabilitation, 14(3),, 375-381.

Riskesdas. (2018). Riset Kesehatan Dasar 2018. Kementrian Kesehatan Republik Indonesia, 1-100. https://doi.org/1 Desember 2013

Rosdiana, I., \& Cahyati, Y. (2019). Effect of Progressive Muscle Relaxation (Pmr) on Blood Pressure Among Patients With Hypertension. International Journal of Advancement in Life Sciences Research, 2(1), 28-35. https://doi.org/10.31632/ijalsr.2019v02i01.005

Seyedi Chegeni, P., Gholami, M., Azargoon, A., Hossein Pour, A. H., Birjandi, M., \& Norollahi, H. (2018). The effect of progressive muscle relaxation on the management of fatigue and quality of sleep in patients with chronic obstructive pulmonary disease: A randomized controlled clinical trial. Complementary Therapies in Clinical Practice, 31, 64-70. https://doi.org/10.1016/j.ctcp.2018.01.010

Shin, J., Yeo, S., Hong, J. Y., Hwang, J. H., \& Kim, S. H. (2018). Impact of intradialytic blood pressure changes on cardiovascular outcomes is independent of the volume status of maintenance hemodialysis patients. Journal of the American Society of Hypertension, 12(11), 779-788. https://doi.org/10.1016/j.jash.2018.06.011

Shinde, V., Kini, R., Naik, R., \& Desousa, A. (2015). A Study on the Effect of Relaxation Techniques and Shavasana on Stress and Pulse Rates of Medical Students. Journal of Exercise Science and Physiotherapy, 11(2), 123. https://doi.org/10.18376//2015/v11i2/67711

Smeltzer, S.C., Bare, B.G., Hinkle, J.L., \& Kerry, H. C. (2015). Brunner \& Suddarth. Brunne-Suddarth infermieristica medico-chirurgica.

Sulaeman, R., Muhasidah, -, Purnamawati, D., Zulkifli, -, Jafar, S. R., \& Suiraoka, I. P. (2018). Progressive muscle relaxation using video aids reduces blood pressure of hypertension patients. International Journal of Health Sciences, 2(3), 33-42. https://doi.org/10.29332/ijhs.v2n3.214

Tomson, C., \& Taylor, D. (2015). Management of chronic kidney disease. Medicine (United Kingdom), 43(8), 454-461. https://doi.org/10.1016/j.mpmed.2015.05.004

Trapp, M., Trapp, E. M., Egger, J. W., Domej, W., Schillaci, G., Avian, A., ... Baulmann, J. (2014). Impact of mental and physical stress on blood pressure and pulse pressure under normobaric versus hypoxic conditions. PLoS ONE, 9(5), 1-7. https://doi.org/10.1371/journal.pone.0089005

Ublosakka-Jones, C., Tongdee, P., Pachirat, O., \& Jones, D. A. (2018). Slow loaded breathing training improves blood pressure, lung capacity and arm exercise endurance for older people with treated and stable isolated systolic hypertension. Experimental Gerontology, 108(December 2017), 48-53. https://doi.org/10.1016/j.exger.2018.03.023

Valika, A., \& Peixoto, A. J. (2016). Hypertension Management in Transition: From CKD to ESRD. Advances in Chronic Kidney Disease, 23(4), 255261. https://doi.org/10.1053/j.ackd.2016.02.002 